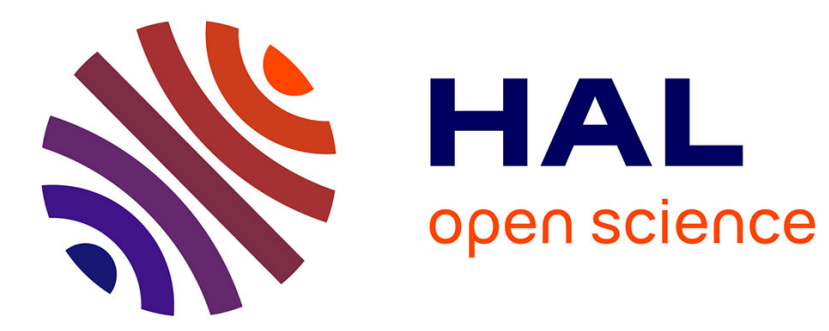

\title{
Seismic wave amplification: Basin geometry vs soil layering.
}

Jean François Semblat, A. Kham, E. Parara, Pierre-Yves Bard, K. Pitilakis, K. Makra, D. Raptakis

\section{- To cite this version:}

Jean François Semblat, A. Kham, E. Parara, Pierre-Yves Bard, K. Pitilakis, et al.. Seismic wave amplification: Basin geometry vs soil layering.. Soil Dynamics and Earthquake Engineering, 2005, 25 (7-10) Special Iss., pp.529-538. 10.1016/j.soildyn.2004.11.003 . hal-00107884

\section{HAL Id: hal-00107884 \\ https://hal.science/hal-00107884}

Submitted on 23 Mar 2009

HAL is a multi-disciplinary open access archive for the deposit and dissemination of scientific research documents, whether they are published or not. The documents may come from teaching and research institutions in France or abroad, or from public or private research centers.
L'archive ouverte pluridisciplinaire HAL, est destinée au dépôt et à la diffusion de documents scientifiques de niveau recherche, publiés ou non, émanant des établissements d'enseignement et de recherche français ou étrangers, des laboratoires publics ou privés. 


\title{
Seismic Wave Amplification : Basin Geometry vs Soil Layering
}

\author{
J. F. Semblat ${ }^{1}$, M. Kham ${ }^{2}$, E. Parara ${ }^{1}$, P. Y. Bard ${ }^{2}$, K. Pitilakis ${ }^{3}$, K. Makra ${ }^{4}$, D. Raptakis ${ }^{3}$ \\ ${ }^{1}$ Laboratoire Central des Ponts et Chaussées (LCPC), Paris, France \\ ${ }^{2}$ LCPC/LGIT, University of Grenoble, France \\ ${ }^{3}$ Department of Civil Engineering, University of Thessaloniki, Greece \\ ${ }^{4}$ Institute of Engineering Seismology (ITSAK), Thessaloniki, Greece
}

\begin{abstract}
The main purpose of the paper is to analyze seismic site effects in alluvial basins and to discuss the influence of the knowledge of the local geology on site amplification simulations. Wave amplification is due to a combined effect of impedance ratio between soil layers and surface wave propagation due to the limited extent of the basin. In this paper, we investigate the influence of the complexity of the soil layering (simplified or detailed layering) on site effects in both time and frequency domain. The analysis is performed by the Boundary Element Method. The European test site of Volvi (Greece) is considered and 2D amplification in the basin is investigated for various soil models. Seismic signals are computed in time domain for synthetic Ricker signals as well as actual measuremens. They are analyzed in terms of amplification level as well as time duration lengthening (basin effects) for both SH and SV waves. These results show that the geometry of the basin has a very strong influence on seismic wave amplification in terms of both amplification level and time duration lengthening. The combined influence of geometry/layering of alluvial basins seems to be very important for the analysis of 2D (3D) site effects but a simplified analysis could sometimes be sufficient. In the case of Volvi European test site, this influence leads to (measured and computed) 2D amplification ratios far above 1D estimations from horizontal layering descriptions.
\end{abstract}

Keywords: seismic waves, wave propagation, site effects, amplification, basin effects, 2D modeling, Euroseitest, BEM

\section{$1 \quad$ Analysis of site effects}

Seismic site effects is a major issue in the field of earthquake engineering since the local amplification of the seismic motion is often very large $[1,2,3,11,17$, $21,22,28,33,34]$. These phenomena can strengthen the incident seismic motion and increase the consequences on structures and buildings. To analyze site effects, it is possible to consider modal approaches $[1,10,19,31$, 32] or directly investigate wave propagation phenomena $[5,6,8,18,24,25,27,29,30]$.

In this paper, we will consider a numerical analysis based on the Boundary Element Method and allowing a complete description of the amplification process [29]. The main advantage of this method is that it allows an accurate description of the infinite extension of the medium $[4,9]$. Furthermore, it does not involve such drawbacks as numerical dispersion a typical, but controllable, numerical error in finite difference or finite element methods $[13,26]$. Thanks to the capabilities of the BEM, we will consider herein two-dimensional basin models of Volvi EuroSeisTest at the scale of several kilometers in width and several hundred meters in depth.

\section{The Volvi EuroSeisTest}

The European test site EuroSeisTest located in Volvi (Greece) was created through grants of the European Commission in the framework of the research programme "Global Change and Natural Disasters » $[14,23]$. The research programme EuroSeisRisk aims at investigating site effects and soil-structure interaction through this test site (http://euroseis.civil.auth.gr).
The EuroSeisTest is located in an alluvial valley at $30 \mathrm{~km}$ north-east of the city of Thessaloniki in Greece (Figure 1). It is an active sismotectonic area where the large 1978 Thessaloniki earthquake occurred. The basin is $6 \mathrm{~km}$ long and $200 \mathrm{~m}$ deep.

One of the main goal of the test site is to have a detailed knowledge of the soil layering and to make the link with seismic wave amplification. More widely, the interest of the test site is to perform experimental and theoretical researches in the fields of geology, seismology, soil and structural dynamics.

Permanent and temporary sensors arrays are used on the test site to measure actual (earthquakes) as well as artificial dynamic loadings.

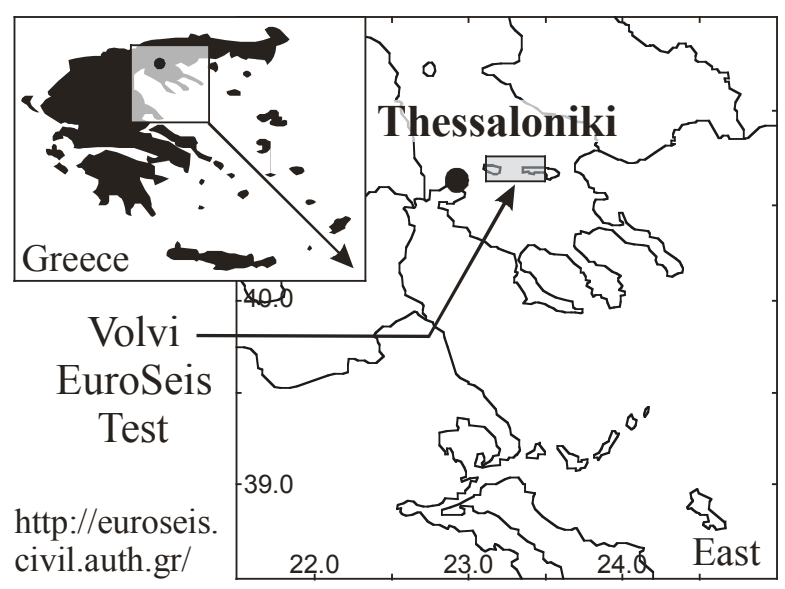

Fig. 1. Map of the Volvi area showing the EuroSeisTest. 
Geotechnical and geophysical analyses of the site conditions are numerous and it is known in details. These analyses were performed at the test site or in the lab. Consequently, the soil properties are well-known and fully reliable.

\section{Simplified and complete models of the Volvi basin}

\subsection{Numerical BEM analysis}

To analyze the seismic response of an alluvial basin, a numerical model based on the boundary element method [4,9] is considered. Through this numerical method, radiation conditions of seismic waves at infinity are fulfilled. The solution of the integral equation is obtained by finite boundary elements discretization and then by collocation [35], that is application of the integral equation at each node of the mesh. The dynamic problem is analyzed in two dimensions and the computations are performed using the FEM/BEM code CESAR-LCPC [12].

\subsection{Various models for the Volvi basin}

For the Volvi test site, several geotechnical models have been proposed. In this paper, we will choose one of them and derive two numerical models: a simplified one with only two soil layers and a complete one with six soil layers. The main goal is to investigate the influence of the knowledge of the local geology on site effects computations.

At LCPC, we chose the basin model proposed by LGIH (Eng. Geology Laboratory, Hydrogeology and Geophysical Prospecting) from the University of Liège (Belgium). This geotechnical model is depicted in Figure 2 with a correction giving an horizontal free surface but respecting layers depths as proposed by P.Y. Bard (LCPC/LGIT, University of Grenoble). Other geological models were also proposed by Raptakis and Chávez-Garcia [22] and were used for 2D analyses of site effects [8].

In this paper, as suggested in the work of Makra et al. [16], we firstly consider a simplified model with only two layers on an elastic bedrock. The layers of the geotechnical model of Figure 2 are combined to derive a simplified two-layer model with thicker soil layers supposed to be equivalent to the actual soil layering as far as site effects are concerned. The mechanical properties of the simplified model are given in Table I and are estimated as mean velocity values of the velocities of the detailed profile. The complete model directly corresponds to Figure 2 (actual layering) with six different layers on an elastic bedrock. The mechanical properties of the complete basin model are detailed in Table II. The purpose of the paper is to analyze seismic wave amplification for the Volvi basin and compare both models towards site effects and especially basin effects.
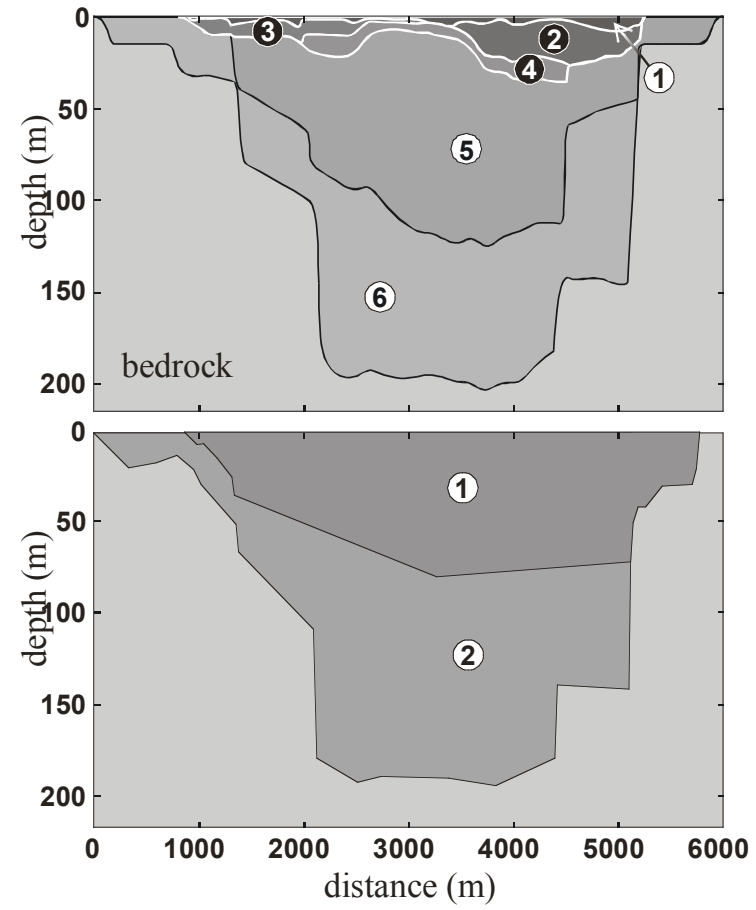

Fig. 2. Geotechnical models of the Volvi basin : complete model (top) and simplified model (bottom).

\section{SH wave amplification in the Volvi basin}

\subsection{Amplification in the basin}

In this section, the seismic excitation is a plane $\mathrm{SH}$ wave with vertical incidence. Since the BEM computation are performed in frequency domain, we can easily derive the amplification factor of the seismic motion in the basin. For the simplified model, amplification values in the basin are given in Figure 3 for various frequencies. The main features of the amplification patterns are as follows:

- For $0.6 \mathrm{~Hz}$ : the largest amplification occurs in the deepest part of the basin and this case seems to correspond to the fundamental mode of vibration of the basin. Nevertheless the maximum amplification factor is not very high since it is below 3

- For $0.8 \mathrm{~Hz}$ : two areas of large amplification appear along the free surface in the central part of the basin with a rather high maximum value (9.5)

- For $1.0 \mathrm{~Hz}$ : maximum amplification is reached at the free surface but the main amplification area (9.5) is shifted to the right in the medium depth part of the basin - For 1.2 Hz: amplification areas also concern the left medium depth part of the basin and the maximum value is slightly lower (7.5)

- For $1.8 \mathrm{~Hz}$ : both free surface and deeper areas reach large amplifications (8.3). The largest amplification corresponds to the extreme left of the medium depth part of the basin

- For $2.4 \mathrm{~Hz}$ : with such wavelengths, the shallow right part of the basin shows large amplifications with both surface and deep processes. There is nearly no amplification in the deepest central part of the basin. 
$\mathrm{F}_{1}=0.6 \mathrm{~Hz}, \mathrm{~A}_{1}=2.9$

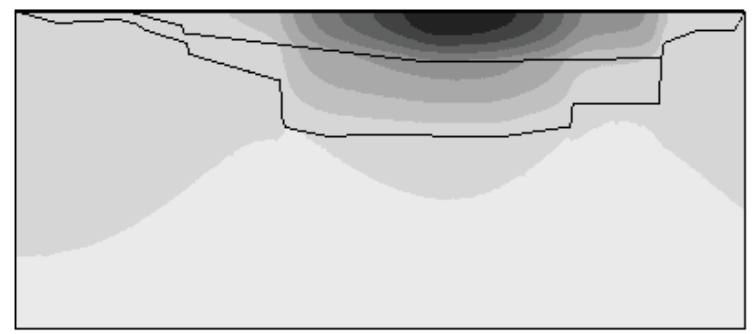

$\mathrm{F}_{3}=1.0 \mathrm{~Hz}, \mathrm{~A}_{3}=9.5$

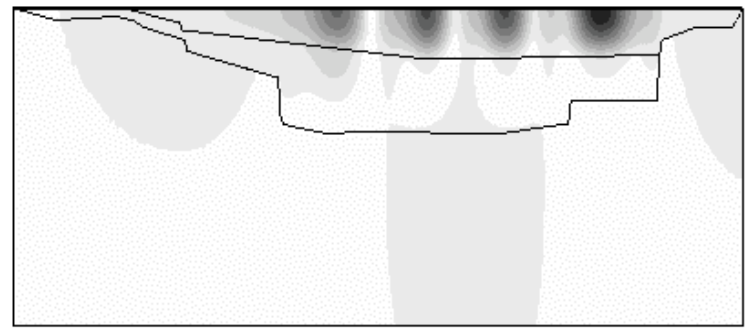

$\mathrm{F}_{5}=1.8 \mathrm{~Hz}, \mathrm{~A}_{5}=8.3$

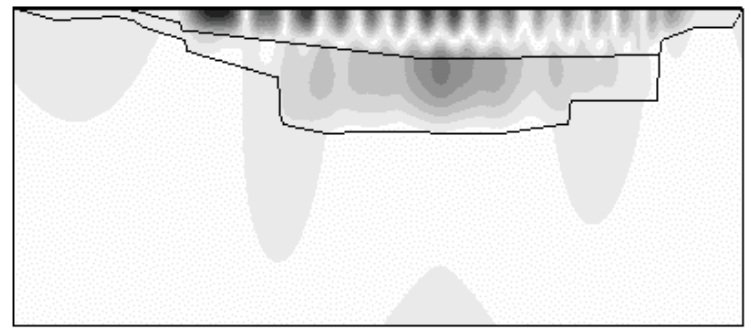

$\mathrm{F}_{2}=0.8 \mathrm{~Hz}, \mathrm{~A}_{2}=9.5$

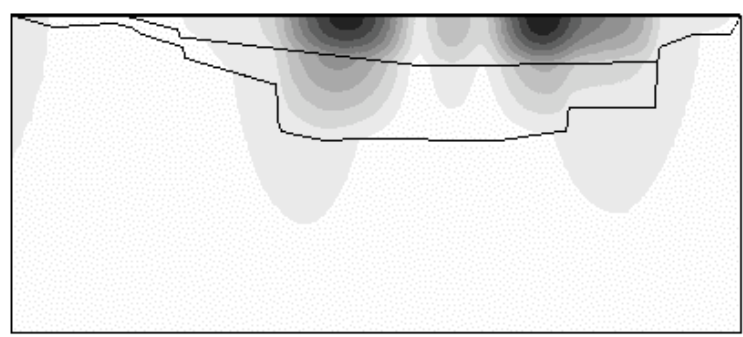

$\mathrm{F}_{4}=1.2 \mathrm{~Hz}, \mathrm{~A}_{4}=7.5$

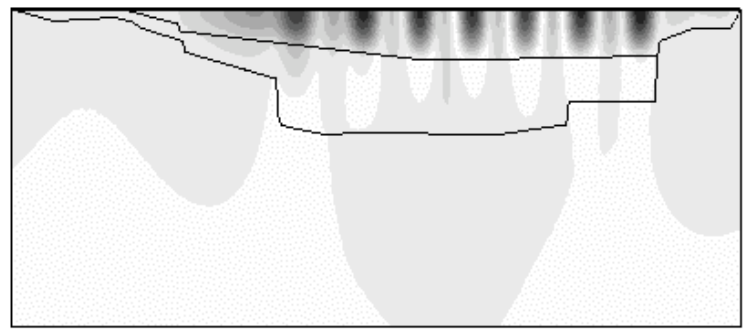

$\mathrm{F}_{6}=2.4 \mathrm{~Hz}, \mathrm{~A}_{6}=7.3$

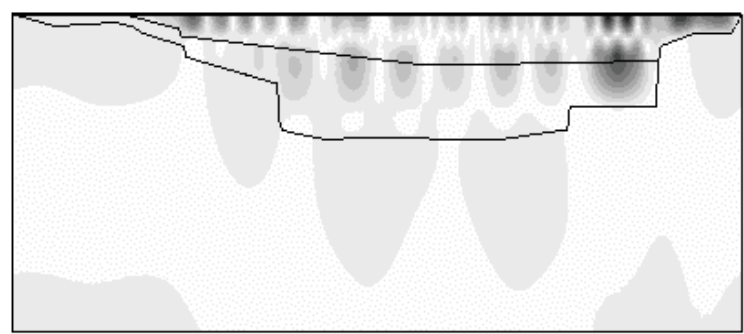

Fig. 3. Amplification values in the basin estimated numerically (simplified basin model) at various frequency (frequency values and related maximum amplifications are given).

TABLE I: PROPERTIES OF THE SOIL LAYERS FOR THE SIMPLIFIED MODEL

\begin{tabular}{cccc}
\hline Soil layers & mass density & $\begin{array}{c}\text { Young's } \\
\text { modulus }\end{array}$ & Poisson's ratio \\
\hline layer 1 & $2100 \mathrm{~kg} / \mathrm{m} 3$ & $677 \mathrm{MPa}$ & 0.280 \\
layer 2 & $2200 \mathrm{~kg} / \mathrm{m} 3$ & $3595 \mathrm{MPa}$ & 0.453 \\
bedrock & $2600 \mathrm{~kg} / \mathrm{m} 3$ & $4390 \mathrm{MPa}$ & 0.249 \\
\hline
\end{tabular}

TABLE II: PROPERTIES OF THE SOIL LAYERS FOR THE COMPLETE MODEL

\begin{tabular}{cccc}
\hline Soil layers & mass density & $\begin{array}{c}\text { Young's } \\
\text { modulus }\end{array}$ & Poisson's ratio \\
\hline layer 1 & $1700 \mathrm{~kg} / \mathrm{m} 3$ & $180 \mathrm{MPa}$ & 0.33 \\
layer 2 & $1800 \mathrm{~kg} / \mathrm{m} 3$ & $300 \mathrm{MPa}$ & 0.33 \\
layer 3 & $1800 \mathrm{~kg} / \mathrm{m} 3$ & $300 \mathrm{MPa}$ & 0.33 \\
layer 4 & $2000 \mathrm{~kg} / \mathrm{m} 3$ & $530 \mathrm{MPa}$ & 0.48 \\
layer 5 & $2200 \mathrm{~kg} / \mathrm{m} 3$ & $1200 \mathrm{MPa}$ & 0.47 \\
layer 6 & $2300 \mathrm{~kg} / \mathrm{m} 3$ & $3300 \mathrm{MPa}$ & 0.49 \\
bedrock & $2600 \mathrm{~kg} / \mathrm{m} 3$ & $4200 \mathrm{MPa}$ & 0.19 \\
\hline
\end{tabular}

\subsection{Basin effects for the simplified and complete models}

The 6 points chosen along the Volvi profile are marked on Figure 4 schematic. They are located at $1000 \mathrm{~m}$ one from each other and these areas correspond to various basin depths. In Figure 4, the amplification/frequency curves are displayed for each of these locations. Solutions for the simplified model are compared to those of the complete model. From these curves, we can make the following comments:

- Point $1(\mathrm{~d}=380 \mathrm{~m})$ : for this location, there is nearly no amplification (at the scale of the maximum amplification curves). The basin depth is small and there is no very soft soil layer at this point

- Point $2(\mathrm{~d}=1380 \mathrm{~m})$ : as shown in Figure 4 and Table III, the maximum amplification is around 9 and is reached for frequency $1.9 \mathrm{~Hz}$. This rather high frequency value can be explained by the moderate depth in this part of the basin 


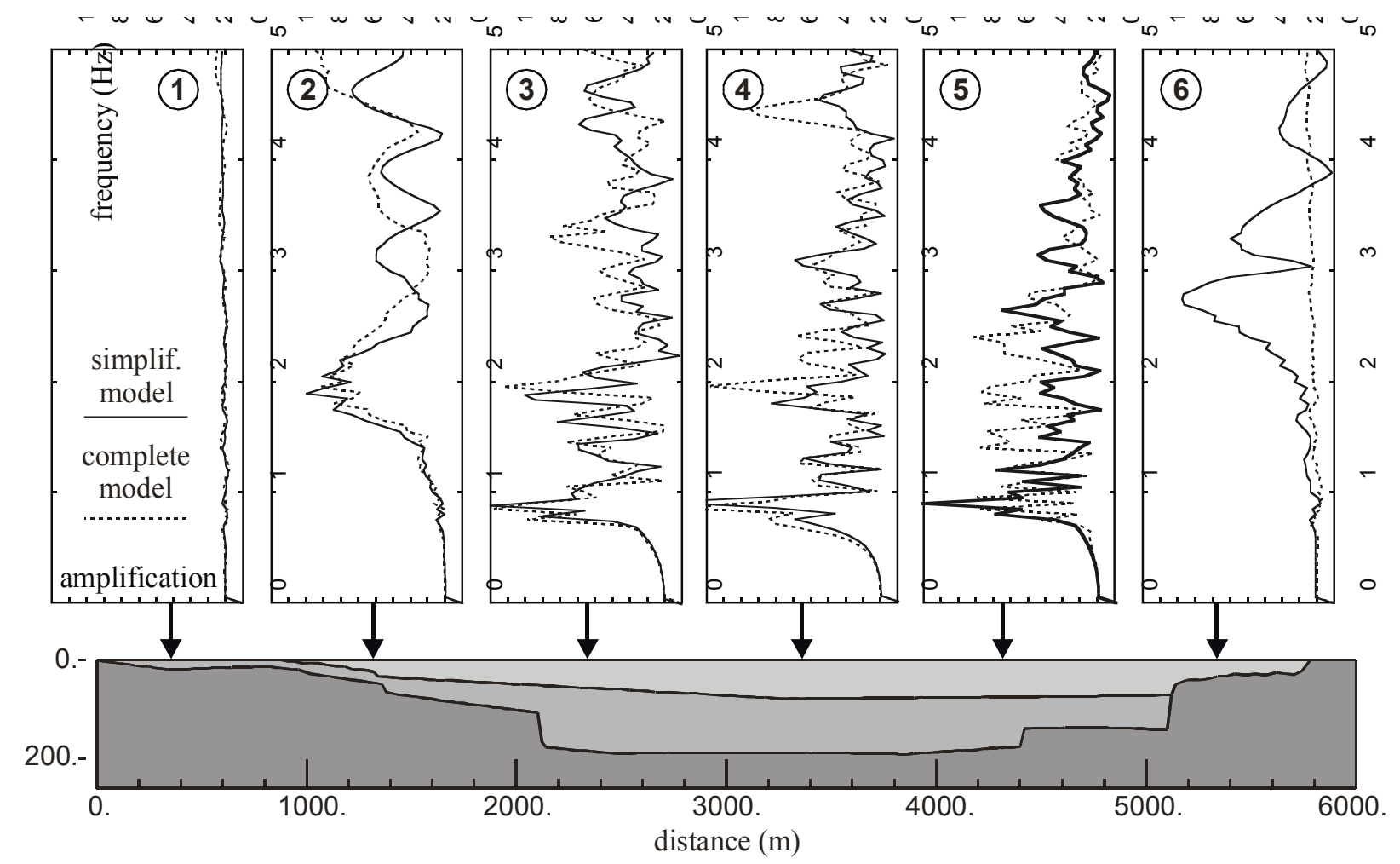

Fig. 4. Amplification/frequency curves for various locations along the basin surface (simplified and complete models).

- Point $3(\mathrm{~d}=2380 \mathrm{~m})$ : there is a large amplification at $0.8 \mathrm{~Hz}$ reaching the maximum value of 11 . This point is in the deepest part of the basin but amplification remains nevertheless significant in the medium frequency range $(\mathrm{f}=1.9 \mathrm{~Hz})$ due to the influence of the shallower left part of the basin which is accurately modeled with the complete model (larger amplification).

- Point $4(\mathrm{~d}=3380 \mathrm{~m})$ : this point is in the central part of the basin and the amplification factor reaches its maximum in a lower frequency range. As shown in Table III, the maximum amplification level is close to the previous ones and the corresponding frequency is identical. For this point, there is also large amplifications around $2.0 \mathrm{~Hz}$ and above $4 \mathrm{~Hz}$ : differences between simplified and complete models are strengthened in the medium frequency ranges, due to the influence of the subsurface layers.

- Point $5(\mathrm{~d}=4380 \mathrm{~m})$ : the maximum amplification (11) corresponds to frequency $0.8 \mathrm{~Hz}$. For this location, amplification for the simplified model is quite low (lower than 6) for other frequencies whereas amplification for the complete model is clearly stronger (around 8) for the medium range frequency. This difference may be due to lateral heterogeneities, particularly strong for the complete model. The amplification pattern at $0.8 \mathrm{~Hz}$ shown in Figure 3 leads to maximum amplification in this particular area

- Point $6(\mathrm{~d}=5380 \mathrm{~m})$ : for this point, the basin depth is slightly smaller than in point 2 but the soil layers are softer. We get significant amplification values for the simplified model and the maximum (9.0) is reached at frequency $2.8 \mathrm{~Hz}$ whereas for the complete model, there is no significant amplification.

The amplification values estimated numerically by the Boundary Element Method are close to experimental ones [21]. When compared to $1 \mathrm{D}$ analysis of amplification [16], 2D estimations lead to larger values since the actual amplification process is strongly influenced by lateral heterogeneities (see following sections). These effects are clear in our numerical results (Figure 4) and we will investigate afterwards their influence on time domain response and seismic signal duration.

TABLE III: VALUES OF BOTH MAXIMUM AMPLIFICATION AND RELATED FREQUENCIES FOR THE SIX LOCATIONS CONSIDERED

\begin{tabular}{cccc}
\hline point & distance & $\begin{array}{c}\text { maximum } \\
\text { amplification }\end{array}$ & $\begin{array}{c}\text { corresponding } \\
\text { frequency }\end{array}$ \\
\hline 1 & $380 \mathrm{~m}$ & $\sim 1$ & \\
2 & $1380 \mathrm{~m}$ & 9.0 & $1.9 \mathrm{~Hz}$ \\
3 & $2380 \mathrm{~m}$ & 11.0 & $0.8 \& 1.9 \mathrm{~Hz}$ \\
4 & $3380 \mathrm{~m}$ & 11.0 & $0.8 \& 1.9 \mathrm{~Hz}$ \\
5 & $4380 \mathrm{~m}$ & 11.0 & $0.8 \mathrm{~Hz}$ \\
6 & $5380 \mathrm{~m}$ & 9.0 & $2.8 \mathrm{~Hz}$ \\
\hline
\end{tabular}




\section{Comparisons between simplified and complete basin models}

As described in Tables I and II, the simplified model is a two-layers basin over an elastic bedrock whereas the complete model includes 6 different soil layers over the bedrock. The purpose of the comparison is to assess the influence of the soil layering description on seismic wave amplification analysis including basin effects. To compare the simplified basin model to the complete one, we will analyze both frequency and time domain results.
5.1 Comparison of amplification vs frequency and distance for both models (SH wave)

As shown in figure 5, the complete model (6 layers) leads to a larger number of amplification peak on both edges of the basin near faults F1 (South) and F4 (North). These peaks of large amplification are especially located in three different areas:

- $f \in[2-3] \mathrm{Hz}$ and $x=4000 \mathrm{~m}$

$-f \in[3-4] \mathrm{Hz}$ and $x=2500 \mathrm{~m}$

$-f \in[4-5] \mathrm{Hz}$ and $x=1500 \mathrm{~m}$.
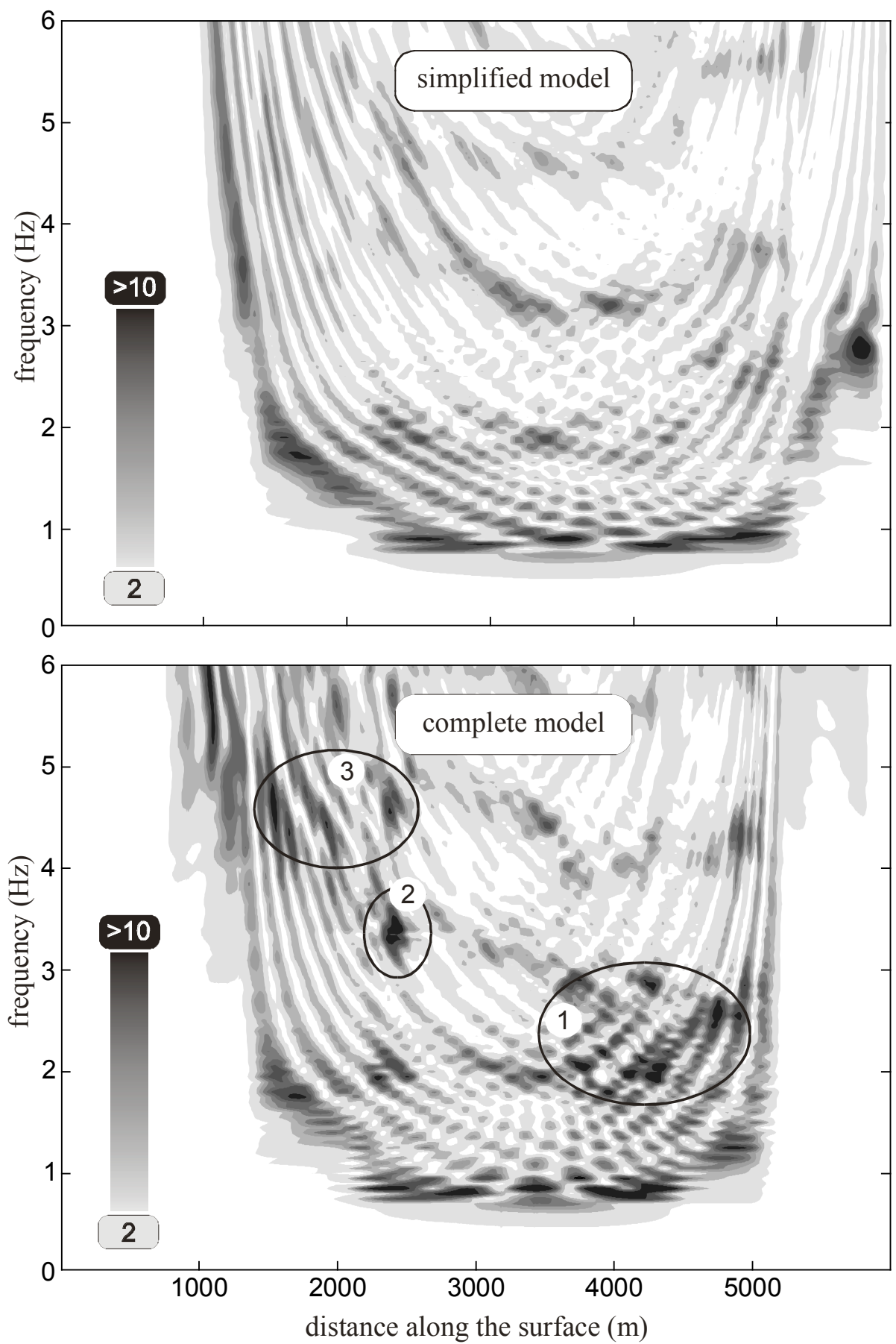

Fig. 5. SH wave amplification vs frequency and distance for the simplified (top) and complete (bottom) models. 
The transfer functions for each basin model are displayed in Figure 5 as isovalues vs distance and frequency. The largest amplification corresponds to the same frequency $f_{0} \approx 0.8 \mathrm{~Hz}$ for both models. It is located in two different areas of the basin. This phenomenon is not due to the near surface layering since the simplified model also shows a "double fundamental mode" [16]. This observation is also made by Chávez-García et al.[8] who suggests that it corresponds to the contribution of surface waves.

\subsection{Comparison for a Ricker time signal (SH wave)}

To fully understand the influence of the basin model description of both vertical and horizontal heterogeneities, we will compute from the previous results the time domain responses at the free surface. For both models (simplified and complete), we consider an upward propagating SH-wave described by a Ricker signal whose spectrum is centered at $1 \mathrm{~Hz}$. From the frequency domain BEM results presented in previous sections, we compute the time domain seismic waves along the free surface. In Figure 6 are displayed the time domain results along the basin for both types of models.

From the time domain solutions derived from the simplified model (top of Figure 6), the amplification process appears clearly. The effect of lateral heterogeneities (basin effects) is obvious since wave reflections on basin edges occur. The amplification of the first arrivals also shows the influence of the velocity contrast in the central (deepest) part of the basin. Seismic wave amplification in the simplified Volvi basin is then influenced by both vertical (soil layering) and lateral (basin effects) heterogeneities.

When comparing with solutions derived from the complete Volvi model (bottom of Figure 6), the amplification of the first arrivals is larger than for the simplified basin model (since the magnitude scale between two following traces is twice of that of the latter model). The soil layering being described more precisely, the amplification due to velocity contrast is then larger. Furthermore, the Ricker signal main wavetrain is combined with reflected and refracted waves to give a more complex wave field (Figure 6). It is especially the case on both left and right sides of the deepest part of the basin. It is possibly due to the combination of vertical and lateral heterogeneities influences. Since the velocity contrasts are described more precisely in the complete model, the lateral wave propagation in each layer is made easier and the global amplification process strengthened. Concerning the signal duration, it is significantly increased showing once more the combined influence of basin effect and soil layering.

The influence of the soil layering of the basin on the amplification process as well as on the signals duration raises the need for a very detailed knowledge of the soil properties and layers geometry. This is a key point to have reliable prediction of surface seismic motion in alluvial deposits.

\subsection{Comparison for a real time accelerogram ( $\mathrm{SH}$ wave)}

We will now consider a real earthquake and compute in time domain the surface motion for both basin models. In this article, only the june 1994 earthquake $(\mathrm{M}=3)$ is presented but other computations for the May 1995 Arnaia earthquake were also performed and are discussed elsewhere [15]. The incident seismic motion is chosen as the reponse at the PRO station (North). As shown in Figure 7, the signals are then computed at all other station locations along the free surface for both simplified and complete models. As previously discussed by Chávez-García et al [7], the quality of the reference station is very important and PRO is the best one in the area but is still located on a very thin alluvial layer [7] approximately at point 1 of figure 4. In Figure 7, the measurements made at the different stations are given (top) for sake of comparison. June 1994 signals are filtered above $6 \mathrm{~Hz}$. The scale of the signals is identical for all cases. Slight differences are observed between measured PRO signals and computed ones because PRO is not a perfect bedrock station [7].

As shown in Figure 7, both models lead to a large amplification of the signals as well as an increase of their duration in the central part of the basin. This trend is in good agreement with the measurements which show a large amplification at the center of the basin.

The complete model generally gives larger amplification (closer to the measurements) since it describes more precisely the soil layering near the free surface. It is especially the case for the GRE station for which the influence of near surface geology appears significant.

As shown in [15], some differences are found considering both earthquakes (june 1994 and may 1995) since the first one involves higher frequencies whereas the second one has a lower frequency content. The accuracy of the basin model is then more important to compute seismic motions of higher frequency content. 

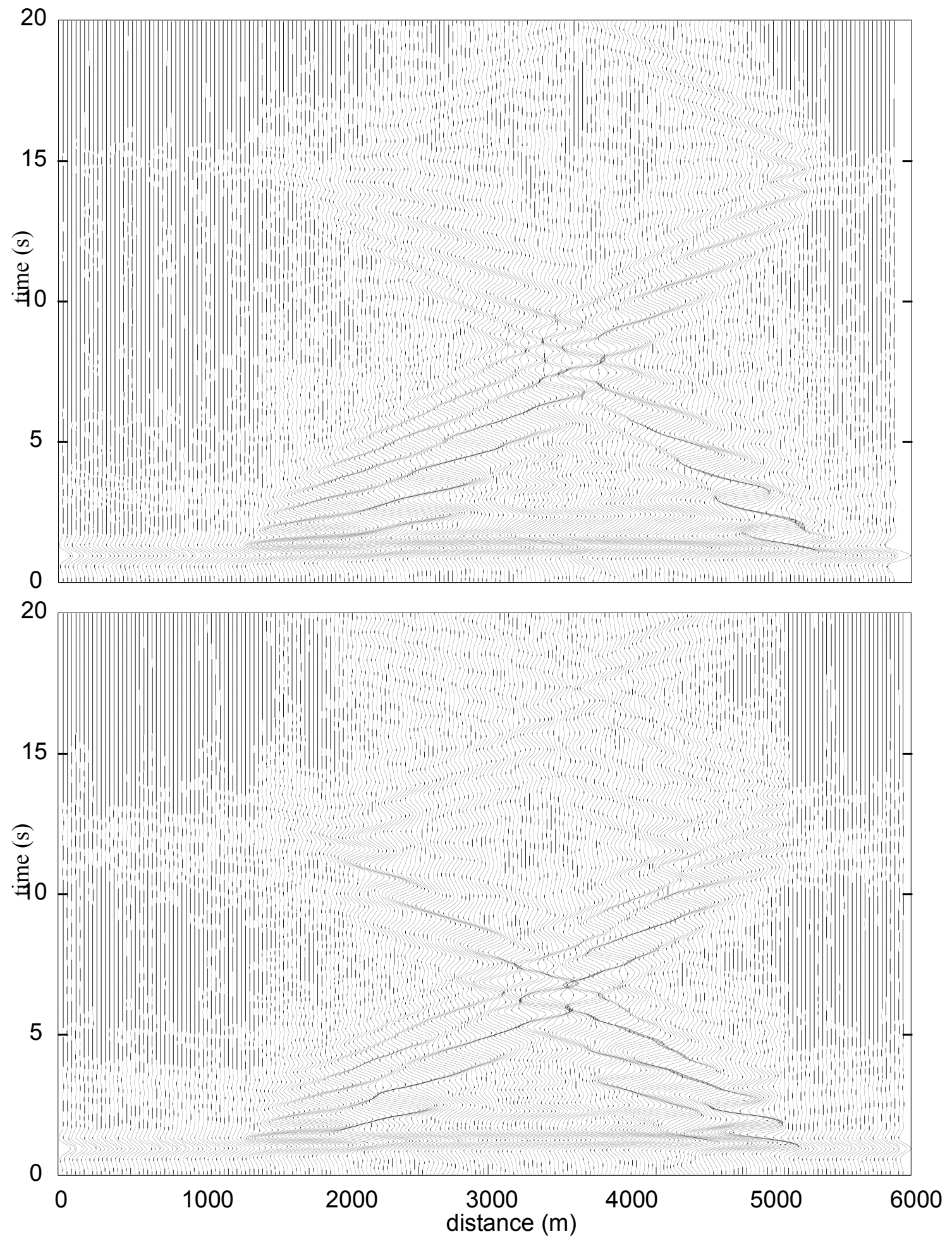

Fig. 6. Time domain signals for the simplified (top) and the complete (bottom) basin models under a 1Hz Ricker excitation. 

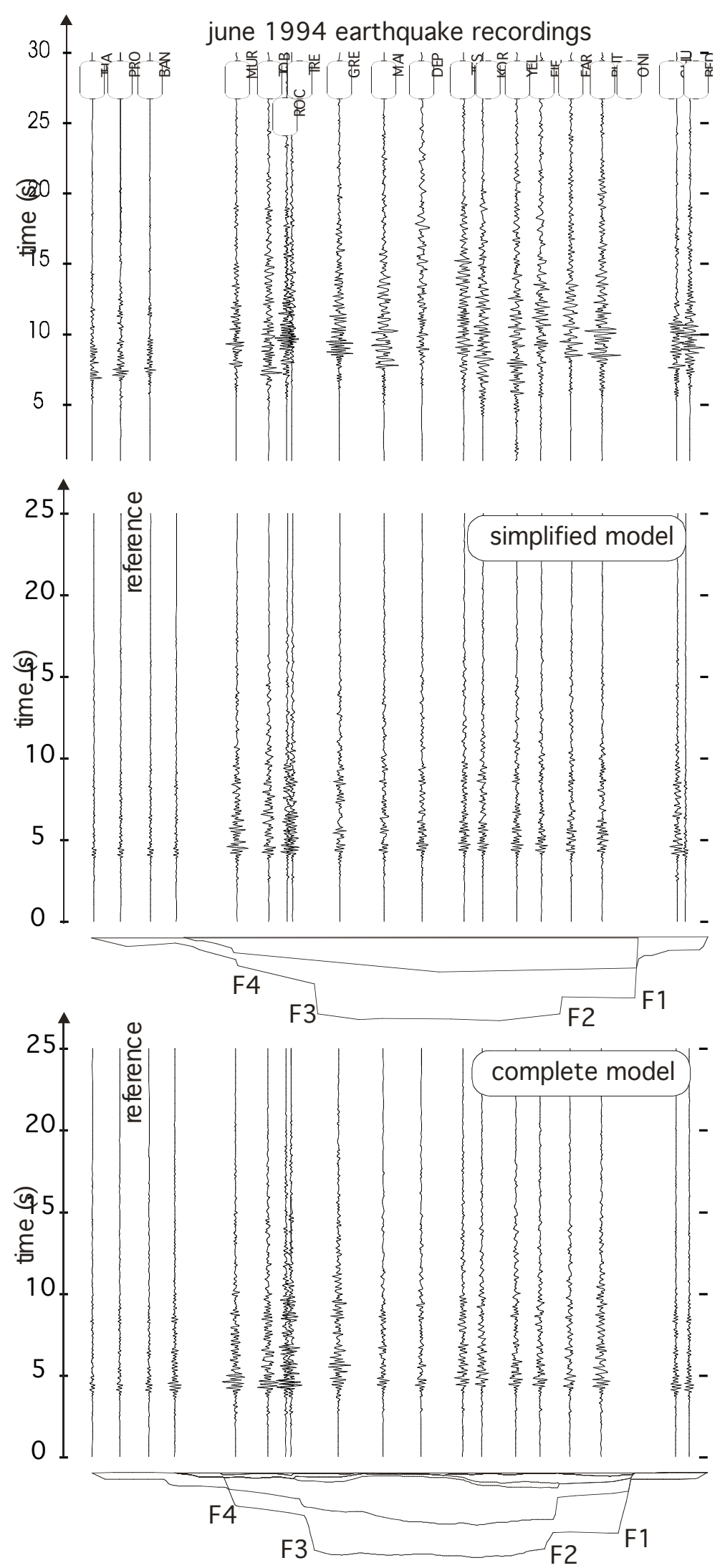

Fig. 7. Accelerograms along the basin for the june 1994 earthquake. Comparison with the simplified (top) and the complete (bottom) basin models solutions for the bedrock station (PRO) signal (input). 


\section{SV wave amplification in the Volvi basin}

\subsection{Amplification vs frequency and distance for both horizontal and vertical motions}

We will now consider the amplification of SV waves in the Volvi basin. Figure 8 firstly shows the transfer function of the complete model for a vertical plane SV wave. The amplification of both horizontal and vertical motions is displayed as isovalues vs distance along the free surface and frequency.

The main amplification areas of the horizontal motion of the basin under $\mathrm{SH}$ wave excitation (Figure 5) are recovered in the case of SV wave (Figure 8). Their locations are identical in both distance and frequency : the fundamental resonance mode is located in the center of the basin $\left(x=3500 m\right.$ and $\left.f_{0}=0,8 \mathrm{~Hz}\right)$; a large number of amplification peaks also appears on both sides of the model between faults F4 and F3 ( $x \in$ $[1000-2000] \mathrm{m})$ and faults $\mathrm{F} 2$ and F1 $(x \in[4000-$ $5000] \mathrm{m})$. The corresponding frequency ranges are $f \in$ [ $1-3] \mathrm{Hz}$ and $f \geq 4 \mathrm{~Hz}$ respectively.

In Figure 8, three main amplification areas appear at frequencies $1 \mathrm{~Hz}, 2 \mathrm{~Hz}$ and $3 \mathrm{~Hz}$ (resp.) all along the basin width. They correspond to the contribution of the main surface geological structures at lower depths for larger frequencies. Thus, the third amplification area at $3 \mathrm{~Hz}$ is linked to the resonance of superficial layers well described by the complete model. This superficial resonance was not so strong in the case of $\mathrm{SH}$ waves (Figure 5).

The transfer function of the vertical motion gives even more interesting results, since it shows $2 \mathrm{D}$ effects due to wave conversion and surface waves generation. Two particular areas can be noticed :

- The first amplification area, ranging from frequencies 1 and $2 \mathrm{~Hz}$ and distances $2500 \mathrm{~m}$ and $4500 \mathrm{~m}$, confirms 2D effects involving the deepest part of the basin.
- The second area, located at large frequencies $(f \geq 3 \mathrm{~Hz})$ and at the basin edges, is associated to the generation of surface waves.

These areas also correspond to the cases of largest discrepancy between the simplified and the complete model for SH wave excitation. This is a good reason to consider the complete model rather than the simplified one to investigate such detailed amplification processes.

\subsection{Computed vs measured transfer functions (SV wave)}

We will then compare the computed transfer functions of the horizontal motion (complete model) to the spectral ratios of the horizontal motion (north / south) measured at the permanent accelerometric stations (Figure 9). The transfer functions computed for the vertical motion are also displayed.

The transfer functions of horizontal motion are close to that of the SH case : they are strongly amplified for the three stations located between the F2 and F3 faults (GRB, TST and FRM) and less amplified elsewhere (GRA, STC). The maximum amplification can reach values larger than 10 for both horizontal and vertical components. Whereas, for the STC station, the vertical amplification is less than 1 .

The large amplification values for the vertical motion show the influence of 2D effects at the center of the basin corresponding to surface wave propagation and focusing effects.

The fundamental resonance of the basin around $0.8 \mathrm{~Hz}$ is quite obvious for the three stations located at the center of the basin. It does not appear in the spectral ratio at the GRA station, probably because GRA is located away from the strong depth variation near fault F3.

Both numerical and experimental results for the horizontal motion are in good agreement. For the characterization of the spectral response of the basin, the complete basin model then appears reliable. 

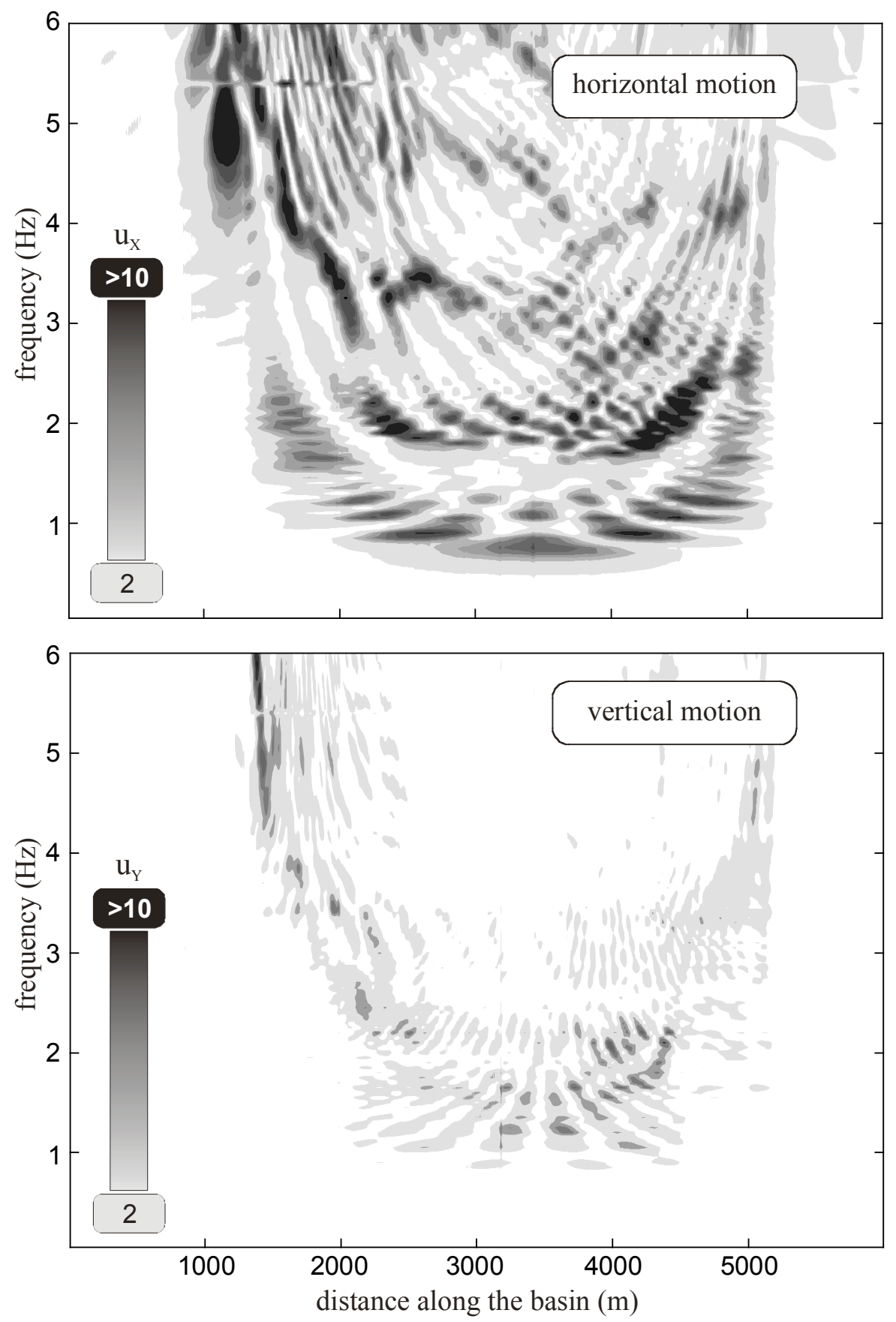

Fig. 8. Transfer function for the complete Volvi basin model under SV wave. The amplification of horizontal (top) and vertical (bottom) motions is displayed as isovalues vs both distance and frequency. 


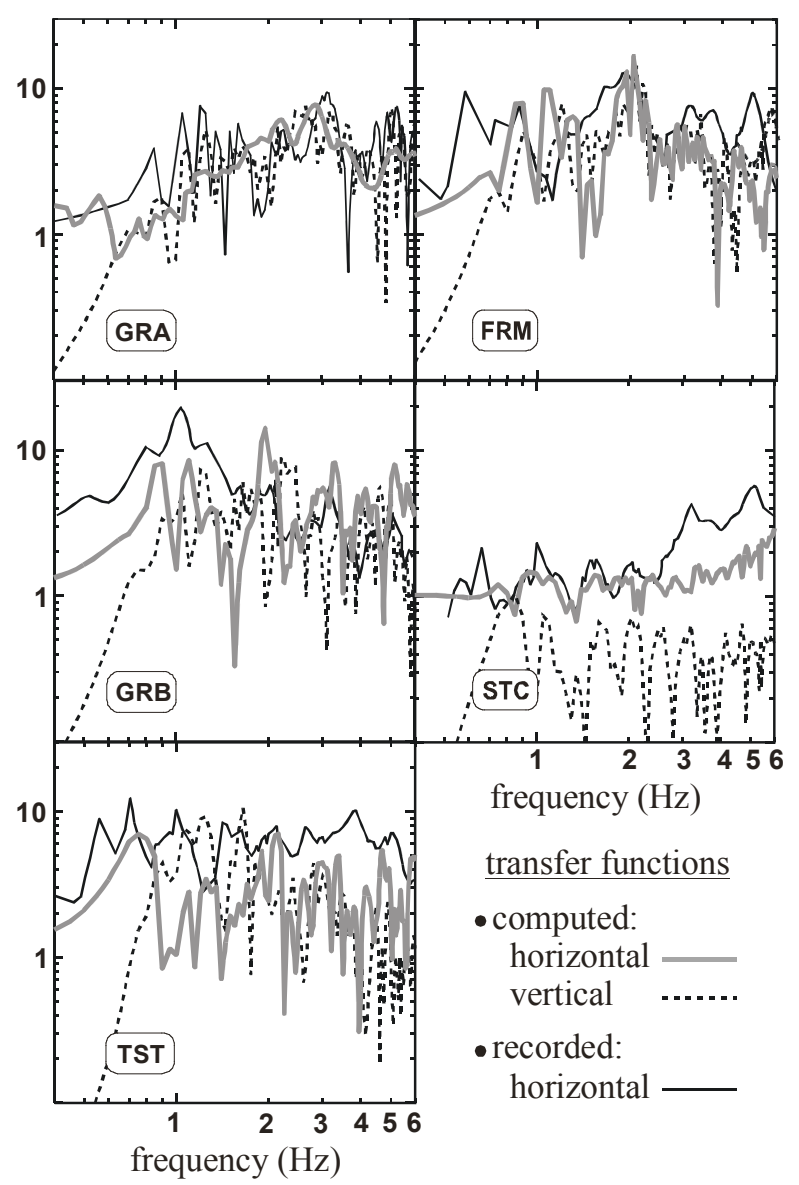

Fig. 9. Transfer functions at the strong motion stations under an SV wave. Comparison between experimental spectral ratios for horizontal motion, the complete model horizontal and vertical transfer functions and 1D horizontal transfer function.

\section{3 \\ Computed vs measured time responses (SV wave)}

In the SV case, the reponse of the basin model will then be analysed for a real earthquake. As in the case of SH wave, we consider the june 1994 earthquake (may 1995 Arnaia earthquake is discussed in [15]). The horizontal measurements at PRO station are taken for the input motion. The computed accelerograms for both horizontal and vertical components are presented in Figure 10. The measurements made at the corresponding stations are displayed for sake of comparison. The scale of acceleration is the same for both motion components.

The numerical results obtained for SV waves are better than for SH wave (Figure 10): the amplification of the seimic motion is stronger in the central part of the basin and is in better agreement with the measured signals.

However, as shown in Figure 10, the amplification is also larger on both edges of the basin between faults F1 and F2 and faults F3 and F4. On this point, the agreement with the measured signals is satisfactory: it shows the reliability of the numerical model to recover realistic seismic motions including complex scattering problems in the topmost alluvial layers. The stronger scattering phenomena near the faults are particularly obvious on the computed vertical motions showing large amplifications of this component.

Finally, the duration of both measured and computed signals are also in good agreement. 

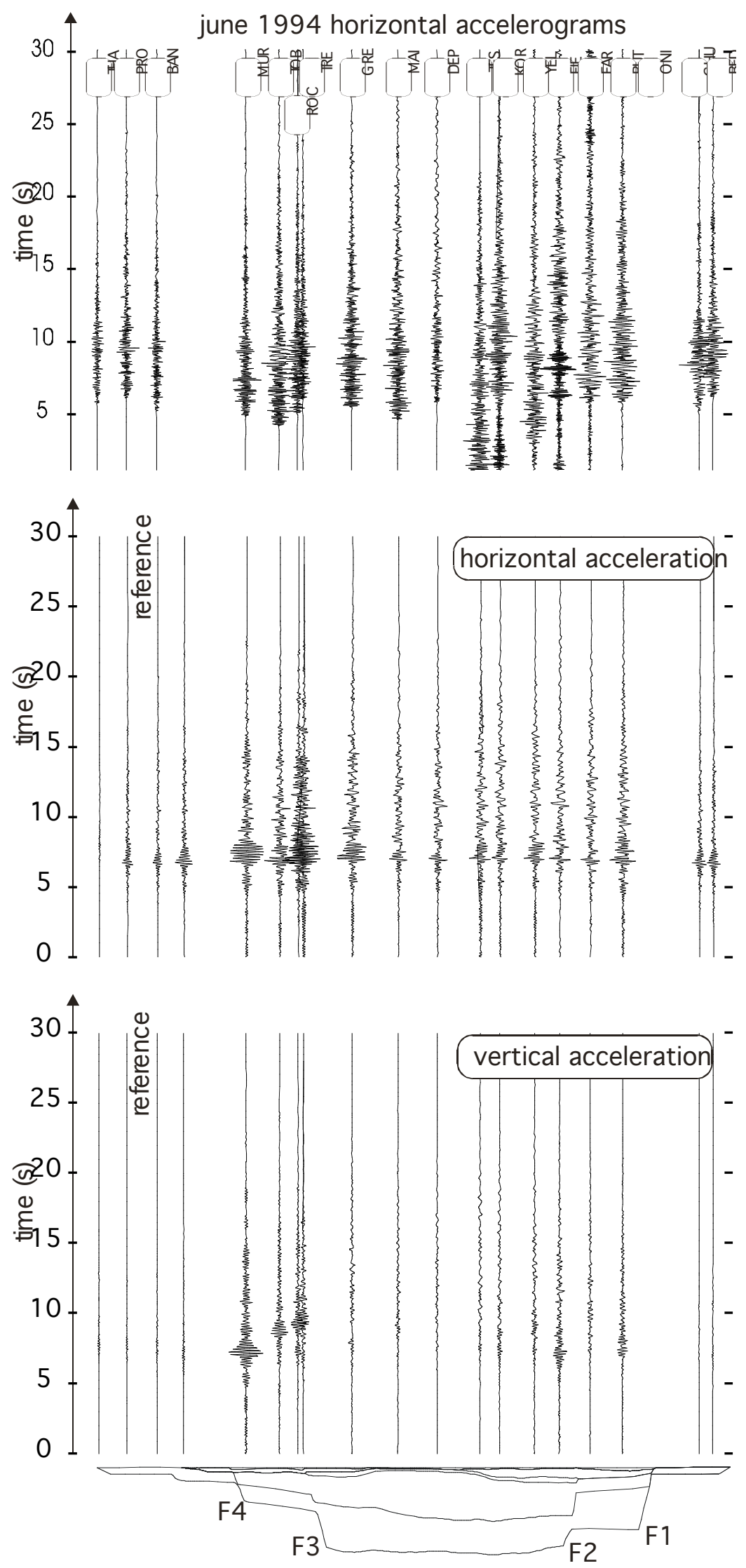

Fig. 10. Accelerograms along the basin for the june 1994 earthquake. Comparison with the complete basin model horizontal (middle) and vertical (bottom) solutions for the bedrock station (PRO) signal as an SV excitation. 


\section{Conclusions}

Starting from simple estimations, such as that provided by modal methods [10, 19, 31, 32], it is then possible to consider a wide variety of numerical models to investigate site effects in alluvial basins. The complexity of these models depends on the available field data as well as the required accuracy and reliability for the target parameters to characterise seismic wave amplification.

In this article, we investigated the seismic response of the Volvi basin (EuroSeisTest) thanks to two different numerical models : a very simplified one not taking into account the topmost alluvial layers and a more complete model including a detailed description of the surface soil layering. The main purpose of this comparison is to discuss the influence of the knowledge of the geological structure of the site on the quality of site effects computations. The main conclusions of the analysis are as follows :

- Both models are reliable to investigate 2D basin effects and the related seismological processes: an increase of the amplification of the seismic motion (when compared to a 1D analysis) and a duration lengthening in the central part of the basin. Both models give a correct estimation of the main resonance of the basin, in both amplitude and frequency.

- The influence of superficial soil layers shown by the complete model (LGIH) is sometimes significant but mainly influences the high frequency content of the signals as well as (trapped) surface waves propagation. The choice of the type of model will then depend on the goal of the analysis in terms of reliability and accuracy.

- The comparison between SV wave amplification and SH wave analysis also shows significant differences between both approaches: the $\mathrm{SH}$ model is rather simple but does not allow to recover the influence of the basin complex geometry (especially around the graben edges) which is quite important on the local amplification of the seismic motion. These aspects, due to the scattering of SV waves, are taken into account in the SV model, but lead to larger computational costs.

- The amplification spectra, commonly used, do not fully describe 2D site effects and give only a partial view of the amplification processes (for instance, complex scattering phenomena or spatial variability of the seismic motion due to surface waves). An accurate description of the subsurface lithology through complete geological models is necessary to make such detailed analyses.

- As discussed by Riepl et al. [23], the influence of the azimuth of the source on the local amplification of the seismic motion seems to be significant. This issue was not discussed in this paper since we wanted to avoid additional focusing effects in both numerical models (due to source location) for sake of easier comparisons. Further analyses [20] involving local sources rather than plane waves (considered herein) will be needed probably for both $2 \mathrm{D}$ and $3 \mathrm{D}$ models.

- Finally, such parameters as the frequency content of the seismic event is also important to make the choice of the most suitable (simplified vs detailed) model.

\section{Acknowledgements}

The authors wish to acknowledge the support of European project "EuroSeisRisk" (EVG1-CT-200100040).

\section{References}

[1] Bard, P.Y., Bouchon, M., "The two dimensional resonance of sediment filled valleys", Bulletin of the Seismological Society of America, 75, pp.519-541, 1985.

[2] Bard, P.Y., Riepl-Thomas, J., "Wave propagation in complex geological structures and their effects on strong ground motion", Wave motion in earthquake eng., Kausel \& Manolis eds, WIT Press, Southampton, Boston, pp.37-95, 2000.

[3] Bielak, J., Xu, J., Ghattas, O., "Earthquake ground motion and structural response in alluvial valleys", Jal of Geotechnical and Geoenvironmental Eng., 125, pp.413-423, 1999.

[4] Bonnet, M., Boundary integral equation methods for solids and fluids, Wiley, Chichester, UK, 1999.

[5] Bouchon, M., "Effects of topography on surface motion", Bull. Seismological Society of America, 63: 615-622, 1973.

[6] R.Chammas, O.Abraham, P.Côte, H.Pedersen, J.F.Semblat, "Characterization of heterogeneous soils using surface waves : homogenization and numerical modeling", International Journal of Geomechanics (ASCE), vol.3, No.1, pp.55-63, 2003.

[7] Chávez-García, F.J., Raptakis, D.G., Makra, K., Pitilakis, K.D., "The importance of the reference station in modelling site effects up to larger frequencies. The case of Euroseistest", $12^{\text {th }}$ European Conf. on Earthquake Eng.., London, 2002.

[8] Chávez-García, F.J., Raptakis, D.G., Makra, K., Pitilakis, K.D., "Site effects at Euroseistest-II. Results from 2D numerical modelling and comparison with observations", Soil Dynamics and Earthquake Eng., 19(1), pp.23-39, 2000.

[9] Dangla, P., "A plane strain soil-structure interaction model", Earthquake Engineering and Structural Dynamics, 16, pp.1115$1128,1988$.

[10] Dobry, R., Oweis, I., Urzua, A., "Simplified procedures for estimating the fundamental period of a soil profile", Bulletin of the Seismological Society of America, 66, pp.1293-1321, 1976.

[11] Duval, A.M., Méneroud, J.P., Vidal, S.and Bard, P.Y., "Relation between curves obtained from microtremor and site effects observed after Caracas 1967 earthquake", 11th European Conf. on Earthquake Engineering, Paris, France, 1998.

[12] Humbert, P., "CESAR-LCPC : a general finite element code" (in French), Bulletin des Laboratoires des Ponts \& Chaussées, 160, pp.112-115, 1989.

[13] Ihlenburg, F., Babuška, I., "Dispersion analysis and error estimation of Galerkin finite element methods for the Helmholtz equation", Int. Journal for Numerical Methods in Engineering, 38, pp.3745-3774, 1995.

[14] Jongmans D., Pitilakis K., Demanet D., Raptakis D., Riepl J., Horrent C., Tsokas G., Lontzetidis K., Bard P.Y. "EuroSeistest: determination of the geological structure of the Volvi basin and validation of the basin response", Bulletin of the Seismological Society of America, 88, pp.473-487, 1998.

[15] Kham M., "Seismic wave propagation in alluvial basins: from site effects to site-city interaction", PhD thesis (in French), Ecole Nationale des Ponts et Chaussée, Paris, 2004.

[16] Makra K., Raptakis D., Chavez-Garcia F.J., Pitilakis K., "How important is the detailed knowledge of a $2 \mathrm{D}$ soil structure for site 
response evaluation?", 12th European Conference on Earthquake Engineering, London, UK, sept.2002.

[17] Moeen-Vaziri, N., Trifunac, M.D., "Scattering and diffraction of plane SH-waves by two-dimensional inhomogeneities", Soil Dynamics and Earthquake Eng., 7(4): 179-200, 1988.

[18] Moczo, P., Bard, P.Y., "Wave diffraction, amplification and differential motion near strong lateral discontinuities", Bulletin of the Seismological Society of America, vol.83, pp.85-106, 1993.

[19] Paolucci, R., "Shear resonance frequencies of alluvial valleys by Rayleigh's method", Earthquake Spectra, 15, pp.503-521, 1999.

[20] Pedersen, H.A., Campillo, M., Sanchez-Sesma, F.J. 1995. Azimuth dependent wave amplification in alluvial valleys, Soil Dynamics and Earthquake Eng. 14(4): 289-300.

[21] Pitilakis, K.D., Raptakis, D.G., Makra, K.A., "Site effects : recent considerations and design provisions", 2nd Int. Conf. on Earthquake Geotechnical Eng., Lisbon, Balkema ed, pp.901-912, 1999.

[22] Raptakis, D.G., Chávez-García, F.J., Makra, K., Pitilakis, K.D. 2000. Site effects at Euroseistest-I. Determination of the valley structure and confrontation of observations with 1D analysis, Soil Dynamics and Earthquake Eng. 19(1): 1-22.

[23] Riepl J., Bard P.Y., Hatzfeld D., Papaioannou, Nechstein S. "Detailed evaluation of site response estimation methods across and along the sedimentary valley of Volvi (EuroSeistest)", Bulletin of the Seismological Society of America, 88, pp.488502, 1998.

[24] Sánchez-Sesma, F.J., "Diffraction of elastic waves by threedimensional surface irregularities", Bull. Seismological Society of America, 73(6), pp.1621-1636, 1983.

[25] Sánchez-Sesma, F.J., Vai, R., Dretta, E., Palencia, V.J., "Fundamentals of elastic wave propagation for site amplification studies", Wave Motion in Earthquake Engineering, E. Kausel and G. Manolis (Editors), WIT Press, Southampton, UK, 1-36, 2000 .

[26] Semblat, J.F. 1997. Rheological interpretation of Rayleigh damping, Jal of Sound and Vibration 206(5): 741-744.

[27] Semblat, J.F., Luong, M.P., "Wave propagation through soils in centrifuge experiments", Journal of Earthquake Engineering, vol.2, No.1, pp.147-171, 1998.

[28] Semblat, J.F., Dangla, P., Duval, A.M. 1999. BEM analysis of seismic wave amplification in Caracas, 7th Int. Symposium on Numerical Models in Geomechanics (NUMOG), Graz, Austria, Balkema ed.: 275-280.

[29] Semblat, J.F., Duval, A.M., Dangla P., "Numerical analysis of seismic wave amplification in Nice (France) and comparisons with experiments", Soil Dynamics and Earthquake Engineering, Vol.19, No.5, pp.347-362, 2000.

[30] Semblat J.F., Dangla P., Kham M., Duval A.M., "Seismic site effects for shallow and deep alluvial basins : in-depth motion and focusing effect", Soil Dynamics and Earthquake Eng., vol.22, No.9-12, pp.849-854, 2002.

[31] Semblat, J.F., Paolucci, R., Duval, A.M., "Simplified vibratory characterization of alluvial basins", Comptes-Rendus Geoscience, vol.335, No.4, pp.365-370, 2003 a.

[32] Semblat J.F., Duval A.M., Dangla P., "Modal superposition method for the analysis of seismic wave amplification", Bulletin of the Seismological Society of America, vol.93, No.3, pp.1144$1153,2003 \mathrm{~b}$

[33] Sommerville, P.G., "Emerging art: earthquake ground motion", ASCE Geotechnical Special Publications, Dakoulas et al eds, 1, pp.1-38, 1998.

[34] Theodulidis, N.P., Bard, P.Y. 1995. Horizontal to vertical spectral ratio and geological conditions: an analysis of strong motion date from Greece and Taiwan (SMART-1), Soil Dynamics and Earthquake Eng. 14(3): 177-197.

[35] Xiao H.H., Dangla P., Semblat J.F., Kham M., "Modelling seismic wave propagation in the frequency domain with analytically regularized boundary integral equations", 5th European Conf. on Numerical Methods in Geotechnical Eng., Paris, 4-6 sept. 2002. 